\title{
Safety of a simplified electrophysiological method of transseptal puncture. A single center's experience
}

\author{
Małgorzata Łodyga, Piotr Urbanek, Michał Orczykowski, Damian Łasocha, Maria Bilińska, \\ Łukasz J. Szumowski \\ Arrhythmia Department, Institute of Cardiology, Warsaw, Poland
}

Adv Interv Cardiol 2018; 14, 2 (52): 183-186

DOI: https://doi.org/10.5114/aic.2018.76410

\section{Introduction}

Transseptal puncture (TSP) is a part of many interventional cardiology procedures including left-sided arrhythmia catheter ablation, transvenous mitral commissurotomy, left atrial appendage occlusion and other catheter-based structural heart disease procedures [1]. Since 1959, when it was first performed [2], different techniques of TSP have been introduced. Guiding methods include fluoroscopy, pressure monitoring [3], intracardiac echocardiography (ICE) [4], transesophageal echocardiography (TEE) [3] and introduction of a pigtail catheter into the aortic root [5].

\section{Aim}

The purpose of this study was to verify the safety of a simplified method of TSP for catheter ablation.

\section{Material and methods}

Data collection and patient population

Six hundred and seventy-four consecutive electrophysiology (EP) procedures requiring TSP between November 2012 and July 2017 were retrospectively analyzed. Exclusion criteria included passing to the left atrium (LA) via a patent foramen ovale. Patients were 51 \pm 15 years old and $36 \%$ were woman. Sixty-five percent suffered from atrial fibrillation (AF), 15\% had an accessory pathway, $13 \%$ left-sided atrial tachycardia, flutter or extrasystole, $7 \%$ ventricular tachycardia, ventricular extrasystole or atrio-ventricular nodal reentry tachycardia (AVNRT). Twenty-nine percent of patients had prior TSP.

\section{Transseptal puncture procedure}

Since the first TSP was performed in our laboratory over 15 years ago it has been done with the same tech- nique regardless of the operator. At the beginning of each procedure all tools are flushed with saline with heparin. A diagnostic catheter is placed in the coronary sinus (CS) as deep as possible to mark the mitral valve plane. In the right anterior oblique (RAO) $30^{\circ}$ view heart rotation in the horizontal plane is assessed (rotation of the apex and mitral valve to determine if the heart lies more horizontally or vertically). A long sheath is introduced over a guidewire into the superior vena cava (SVC). The guidewire is then removed and the puncture needle with a protective stylet is introduced. Needles with very similar curvature were used in $99 \%$ of cases (TSNC by Cook Medical in 53\% and BRK XS by St Jude Medical in 46\%). In $<1 \%$ we used BRK-1 XS by St Jude Medical. With fluoroscopy angled to the left anterior oblique (LAO) $30^{\circ}$ the whole setup is turned so that the needle and the side arm of the sheath are pointing at a 4-5-o'clock position. The setup is than smoothly pulled caudally until two 'jumps' are seen. The first jump marks the shift from the SVC to the right atrium (RA) and the second one to the fossa ovalis. The setup should be superior to the CS ostium. Then the position is confirmed in the RAO $40^{\circ}$ projection, where it should be posterior and parallel to the CS catheter. If they are not parallel or the needle cannot jump to the fossa ovalis the setup should be put back to SVC, rotated and withdrawn again. Posterior movement (clockwise rotation) might be necessary in a large LA, anterior movement (counterclockwise rotation) in hearts positioned more vertically or a smaller LA.

Later, in the LAO position the needle is pushed through the intra-atrial septum (IAS). If blood is aspirated through the needle, a few milliliters (or less) of contrast are administered to confirm that the needle is in the LA. Only then is the sheath with the dilator advanced further. Before introducing the guidewire, another amount

\section{Corresponding author:}

Małgorzata Łodyga, Arrhythmia Department, Institute of Cardiology, 42 Alpejska St, 04-628 Warsaw, Poland, phone: +48 223434417, fax: +48 2234345 20, e-mail: lodyga.m@gmail.com

Received: 2.01.2018, accepted: 5.03.2018. 
of contrast is injected to exclude the possibility that the catheter ostium touches the LA roof or posterior wall (which might occur in a small LA). During difficult TSP (e.g. fibrosed or thick septum) contrast can be injected during the puncture to see the 'tenting' of the IAS before pushing the needle.

In some cases it might be necessary to change the curvature of the needle: a larger curve approximately $10 \mathrm{~cm}$ from the tip could help to reach the IAS in RA enlargement and a larger curve closer to the needle tip might be needed in LA dilatation or when the first TSP attempt was unsuccessful so that the contact with the IAS is better.

\section{Results}

Among 674 analyzed procedures 4 (0.6\%) TSPs were unsuccessful. Only $5(0.75 \%)$ minor complications were reported, of which $2(0.3 \%)$ were due to needle only puncture of the aortic root and $3(0.45 \%)$ of the right atrium free wall. After the contrast was seen in a structure other than the LA the whole setup was withdrawn and the procedure suspended. Transthoracic echocardiography was performed directly to reveal no pericardial bleeding in each case.

No life-threatening complications such as perforation of the aortic root or heart walls or cardiac tamponade occurred. The patients remained asymptomatic.

All 5 patients underwent another successful procedure. The characteristics and management of each patient are presented in Table I.

\section{Discussion}

According to the literature the complication rate during TSP reaches $0.75-2 \%[6,7]$, though not all authors report minor complications (such as needle only puncture of the aortic root or right atrium free wall) so the rate is likely to be higher.

In a single-center study published in 2017 by Matoshvili et al. [8] 4,690 TSPs were reviewed. The procedure was performed with fluoroscopic guidance with contrast injection and pressure monitoring and additional use of TEE or ICE in 27 cases. Thirty-four tamponades were reported, of which 6 could not be related to the TSP, and 14 minor complications. The incidence of tamponades was higher at the beginning of the electrophysiology training.

In a survey conducted by de Ponti et al. [7] TSPs performed in 33 Italian centers were analyzed. Complications are listed in Table II. Five out of the seven centers that reported complications such as cardiac perforation or needle only puncture of the aortic root or atrium free wall were routinely using auxiliary tools (however, the authors do not specify the exact guiding technique used).

A single-center report published in 1994 by Roelke et al. [6] of 1,279 TSPs done with pressure monitoring, contrast injection and a pig tail catheter in the aortic root showed 1 death and 15 tamponades connected to TSP. The authors admit that minor complications such as needle-only punctures of adjacent structures were not reported.

In two papers from high- and medium-volume centers complications during AF ablation procedures were analyzed. Aldhoon et al. [9] reviewed 1,192 procedures, all done under ICE guidance, and reported no complications during TSP. Lee et al. [10] reported no cardiac tamponade connected to TSP during 500 procedures done using TEE, although there are no data on minor TSP complications but 3 complications related to the TEE itself.

Safety and efficacy of a simplified method (TSP without any auxiliary tools, with contrast injection only) was described in 1998 by de Ponti et al. [5], where out of 348 patients only 3 minor complications connected to TSP were reported.

In our laboratory we have used the same TSP technique for more than 15 years. Although we only studied the procedures performed in the last 5 years, no serious complications such as tamponade or aortic root perforation during TSP were ever recorded.

The complication rate in our study was only $0.75 \%$. All complications were minor and none of them required any intervention. What is distinctive is a significant group

Table I. Characteristics and management of patients with complications

\begin{tabular}{|c|c|c|c|c|c|}
\hline Variable & Age & Sex & TSP no. & Arrhythmia & Approach during next procedure \\
\hline \multicolumn{6}{|c|}{ Aortic root puncture: } \\
\hline Patient 1 & 65 & Female & 1 & AP & Successful TSP \\
\hline Patient 2 & 57 & Male & 2 & $\mathrm{AF}$ & Successful TSP with TEE guidance \\
\hline \multicolumn{6}{|c|}{ Right atrium free wall puncture: } \\
\hline Patient 3 & 55 & Male & 1 & VT & Transaortic approach \\
\hline Patient 4 & 54 & Male & 1 & $\mathrm{AF}$ & Successful TSP \\
\hline Patient 5 & 19 & Male & 1 & AT & Passing through foramen ovale \\
\hline
\end{tabular}

AF-atrial fibrillation, AP-accessory pathway, VT - ventricular tachycardia, TEE - transesophageal echocardiography, TSP - transseptal puncture. 
Table II. Incidence of TSP complications

\begin{tabular}{|c|c|c|c|c|c|c|c|c|}
\hline \multirow[t]{2}{*}{ Reference } & \multirow{2}{*}{$\begin{array}{c}\text { De Ponti } \\
\text { et al. } 1998 \\
{[5]}\end{array}$} & \multirow{2}{*}{$\begin{array}{l}\text { Matoshvili } \\
\text { et al. [8] }\end{array}$} & \multicolumn{2}{|c|}{ De Ponti et al. [7] } & \multirow{2}{*}{$\begin{array}{l}\text { Roelke } \\
\text { et al. [6] }\end{array}$} & \multirow{2}{*}{$\begin{array}{l}\text { Aldhoon } \\
\text { et al. [9] }\end{array}$} & \multirow{2}{*}{$\begin{array}{l}\text { Lee } \text { et al. } \\
\quad[10]\end{array}$} & \multirow{2}{*}{$\begin{array}{l}\text { todyga } \\
\text { et al. }\end{array}$} \\
\hline & & & 2003 & $1992-2002$ & & & & \\
\hline Technique & $\begin{array}{l}\text { Contrast } \\
\text { injection }\end{array}$ & $\begin{array}{c}\text { Pressure } \\
\text { monitoring, } \\
\text { contrast } \\
\text { injection. ICE } \\
\text { or TEE }\end{array}$ & \multicolumn{2}{|c|}{$\begin{array}{l}\text { Pressure monitoring, pig } \\
\text { tail catheter, ICE or TEE }\end{array}$} & $\begin{array}{c}\text { Contrast } \\
\text { injection, } \\
\text { pressure } \\
\text { monitoring, } \\
\text { pig tail } \\
\text { catheter }\end{array}$ & ICE & TEE & $\begin{array}{l}\text { Contrast } \\
\text { injection }\end{array}$ \\
\hline $\begin{array}{l}\text { Complications/ } \\
\text { procedures }\end{array}$ & $\begin{array}{l}3 / 348 \\
(0.9 \%)\end{array}$ & $\begin{array}{l}42 / 4690 \\
(0.9 \%)\end{array}$ & $\begin{array}{c}14 / 1764 \\
(0.8 \%)\end{array}$ & $\begin{array}{c}28 / 3756 \\
(0.7 \%)\end{array}$ & $\begin{array}{c}17 / 1279 \\
(1.3 \%)\end{array}$ & 0/1192 & $0 / 500$ & $5 / 674(0.7 \%)$ \\
\hline Death & - & - & - & $1(<0.1 \%)$ & $1(0.1 \%)$ & - & - & - \\
\hline Tamponade & - & $28(0.6 \%)$ & $2(0.1 \%)$ & $3(0.1 \%)$ & $15(1.2 \%)$ & - & - & - \\
\hline $\begin{array}{l}\text { Aortic root } \\
\text { perforation }\end{array}$ & - & - & - & $3(0.1 \%)$ & $\mathrm{n} / \mathrm{a}$ & - & $\mathrm{n} / \mathrm{a}$ & - \\
\hline $\begin{array}{l}\text { Cardiac } \\
\text { perforation }\end{array}$ & - & - & $3(0.2 \%)$ & $3(0.1 \%)$ & $\mathrm{n} / \mathrm{a}$ & - & $n / a$ & - \\
\hline $\begin{array}{l}\text { Right atrium free } \\
\text { wall puncture }\end{array}$ & $2(0.6 \%)$ & $11(0.2 \%)$ & $4(0.2 \%)$ & $9(0.2 \%)$ & $n / a$ & - & $\mathrm{n} / \mathrm{a}$ & $3(0.4 \%)$ \\
\hline $\begin{array}{l}\text { Aortic root } \\
\text { puncture }\end{array}$ & - & $3(0.1 \%)$ & $1(0.1 \%)$ & $1(<0.1 \%)$ & $n / a$ & - & $n / a$ & $2(0.3 \%)$ \\
\hline $\begin{array}{l}\text { Thromboembo- } \\
\text { lism/TIA/stroke }\end{array}$ & $1(0.3 \%)$ & - & $1(0.1 \%)$ & $3(0.1 \%)$ & $1(0.1 \%)$ & - & - & - \\
\hline Air embolism & - & - & - & $2(0.1 \%)$ & - & - & $n / a$ & - \\
\hline $\begin{array}{l}\text { ST-segment } \\
\text { elevation }\end{array}$ & - & - & $3(0.2 \%)$ & $2(0.1 \%)$ & - & - & $\mathrm{n} / \mathrm{a}$ & - \\
\hline Pericarditis & - & - & - & $1(<0.1 \%)$ & - & - & $\mathrm{n} / \mathrm{a}$ & - \\
\hline Unsuccessful TSP & $5(1.4 \%)$ & $14(0.3 \%)$ & $11(0,6 \%)$ & $19(0.5 \%)$ & $16(1.3 \%)$ & $\mathrm{n} / \mathrm{a}$ & $\mathrm{n} / \mathrm{a}$ & $4(0.6 \%)$ \\
\hline
\end{tabular}

of patients who had one or more TSP prior to our procedure $(29 \%)$, which is known as a possible complication factor $[11,12]$.

The rate of cardiac tamponade as a complication of TSP differs among studies and ranges from 0 to $1.2 \%$. Cardiac tamponade related to TSP is usually the result of a cardiac wall perforation [13], but needle-only puncture of the pericardium, if recognized before the sheath is pushed forward, usually does not lead to cardiac tamponade [6]. Also needle-only puncture of the aortic root usually has no sequelae. The incidence of inadvertent sheath placement in the aorta during TSP is low (0.05-0.08\%), but can result in aortic root perforation [7]. Therefore it is important to recognize that the needle is in an inappropriate structure before introducing the sheath and stop the procedure at this point.

As shown above, it is not evidently proved that usage of any auxiliary tool for TSP guiding is associated with a lower complication rate, and the "simplified method" can also have a high safety rate. The factor that is shown as reducing complications is the operator's experience $[7,8]$. Many authors also stress that TSP is a demanding procedure and should be done in centers with a higher volume of cases per year [5].
The use of additional expensive equipment might increase the cost of the ablation procedure, which alone is a major cost factor in arrhythmia treatment in the national health care system [14].

Moreover, to insert a pig-tail catheter in the aorta an artery puncture in needed, TEE requires general anesthesia and another operator and can cause complications itself and experience is needed to interpret ICE images [15].

Furthermore, the ability to perform TSP without TEE or ICE should be helpful when no TSP was planned (and other guiding tools are not available in the EP laboratory) but during the ablation procedure the need to access the LA arises.

\section{Conclusions}

We believe that the safety of the fluoroscopy-only guidance technique that is used in our laboratory is dependent on a few rules that are always obeyed: assessment of cardiac rotation in RAO, checking the needle position in RAO and LAO, blood aspiration through the needle and sheath to lower thromboembolism risk, and terminating the procedure after the contrast is seen in any structure other than the LA. These features are suf- 
ficient to perform a safe and successful TSP even at the beginning of the learning curve.

\section{Conflict of interest}

The authors declare no conflict of interest.

\section{References}

1. Alkhouli M, Rihal CS, Holmes DR. Transseptal techniques for emerging structural heart interventions. JACC Cardiovasc Interv 2016; 9: 2465-80.

2. Ross Jr J, Braunwald E, Morrow AG. Transseptal left atrial puncture. New technique for the measurement of left atrial pressure in man. Am J Cardiol 1959; 3: 653-5.

3. Earley MJ. How to perform a transseptal puncture. Heart 2008; 95: 85-92.

4. Ruisi CP, Brysiewicz N, Asnes JD, et al. Use of intracardiac echocardiography during atrial fibrillation ablation. Pacing Clin Electrophysiol 2013; 36: 781-8.

5. De Ponti R, Zardini M, Storti C, et al. Trans-septal catheterization for radiofrequency catheter ablation of cardiac arrhythmias. Results and safety of a simplified method. Eur Heart J 1998; 19: 943-50.

6. Roelke M, Conrad Smith AJ, Palacios IF. The technique and safety of transseptal left heart catheterization: the Massachusetts General Hospital experience with 1,279 procedures. Cathet Cardiovasc Diagn 1994; 32: 332-9.

7. De Ponti R, Cappato R, Curnis A, et al. Trans-septal catheterization in the electrophysiology laboratory: data from a multicenter survey spanning 12 years. J Am Coll Cardiol 2006; 47: 1037-42.

8. Matoshvili Z, Bastani H, Bourke T, et al. Safety of fluoroscopyguided transseptal approach for ablation of left-sided arrhythmias. EP Europace 2017; 19: 2023-6.

9. Aldhoon B, Wichterle D, Peichl P, et al. Complications of catheter ablation for atrial fibrillation in a high-volume centre with the use of intracardiac echocardiography. EP Europace 2013; 15: 24-32.

10. Lee G, Sparks PB, Morton JB, et al. Low risk of major complications associated with pulmonary vein antral isolation for atrial fibrillation: results of 500 consecutive ablation procedures in patients with low prevalence of structural heart disease from a single center. J Cardiovasc Electrophysiol 2011; 22: 163-8.

11. Tomlinson DR, Sabharwal N, Bashir Y, et al. Interatrial septum thickness and difficulty with transseptal puncture during redo catheter ablation of atrial fibrillation. Pacing Clin Electrophysiol 2008; 31: 1606-11.

12. Marcus GM, Ren X, Tseng ZH, et al. Repeat transseptal catheterization after ablation for atrial fibrillation. J Cardiovasc Electrophysiol 2007; 18: 55-9.

13. Holmes DR, Nishimura R, Fountain R, et al. latrogenic pericardial effusion and tamponade in the percutaneous intracardiac intervention era. JACC Cardiovasc Interv 2009; 2: 705-17.

14. Sierpiński R, Gierczyński J, Gałązka-Sobotka M, et al. Socioeconomic aspects of arrhythmias treatment in Poland in comparison with other EU countries - systematic report. Heart Beat 2016; 1: 83-9.

15. Tzeis S, Andrikopoulos G, Deisenhofer I, et al. Transseptal catheterization: considerations and caveats: review. Pacing Clin Electrophysiol 2010; 33: 231-42. 